\title{
Clinical Outcomes of Endoscope-Assisted Vitreous Surgery for Giant Retinal Tear Detachment
}

\author{
Hayato Mitamuraa,b, c Tatsushi Kagab Sho Yokoyamab ${ }^{b}$ Takashi Kojimad $^{d}$ \\ Toshio Mori $^{a}$ Taisuke Matsuda ${ }^{b}$ Hiroyuki Sato ${ }^{e}$ Norihiko Yoshida ${ }^{f}$ \\ Kazuo Ichikawac

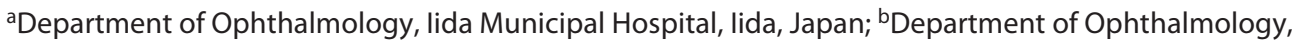 \\ Japan Community Health Care Organization Chukyo Hospital, Nagoya, Japan; 'Chukyo Eye Clinic, Nagoya, Japan;

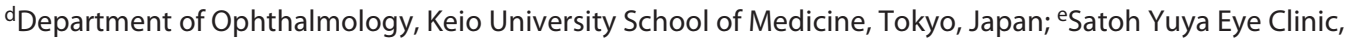 \\ Sendai, Japan; fDepartment of Ophthalmology, Japanese Red Cross Gifu Hospital, Gifu, Japan
}

\section{Keywords}

Ophthalmic endoscopy · Giant retinal tear detachment · Vitrectomy

\begin{abstract}
Introduction: With the advent of perfluorocarbon liquid (PFCL), the success rate of refractory giant retinal tear (GRT) detachment has dramatically improved. PFCL is a very effective tool when used properly, but in GRT detachment, it may move under the retina through the tear, so it is necessary to devise ways to prevent PFCL from migrating under the retina. Ophthalmic endoscope-assisted vitrectomy may reduce the risk of subretinal migration of PFCL, facilitate safer use of PFCL, and increase the success rate of GRT detachment. The present study aimed to describe the clinical outcomes of endoscope-assisted vitreous surgery for giant retinal detachment. Methods: Twenty consecutive eyes from 19 patients who had undergone endoscope-assisted vitreous surgery for treatment of a GRT detachment were enrolled. Subretinal fluid drainage, extension of the rolled GRT, and endophoto-
\end{abstract}

karger@karger.com www.karger.com/ore

Karger $\stackrel{\text { ' }}{5}$

GOPEN ACCESS
(C) 2021 The Author(s)

Published by S. Karger AG, Basel

This is an Open Access article licensed under the Creative Commons Attribution-NonCommercial-4.0 International License (CC BY-NC) (http://www.karger.com/Services/OpenAccessLicense), applicable to the online version of the article only. Usage and distribution for commercial purposes requires written permission. coagulation under air were performed with the aid of an endoscope, without the use of PFCL. Where necessary, extension of a fixed retinal fold and internal limiting membrane peeling was performed with PFCL. Results: The initial and final retinal reattachment rates were 90 and $95 \%$, respectively. In 3 eyes, a small amount of PFCL was used, and there were no PFCL remnants. The mean follow-up duration was 18 months (range, 3-69 months). After surgery, the mean bestcorrelated visual acuity significantly improved from 20/514 to $20 / 41$ ( $p=0.0008$ ). Discussion/Conclusion: Endoscopeassisted vitreous surgery for giant retinal detachment has favourable clinical outcomes for visual acuity and retinal detachment.

(c) 2021 The Author(s)

Published by S. Karger AG, Basel

\section{Introduction}

The treatment of a giant retinal tear (GRT) detachment was technically difficult due to the complexity of unfolding the large retinal flap during the surgery, until 
Table 1. Baseline patient demographic information

\begin{tabular}{|c|c|c|c|c|c|c|c|c|c|c|}
\hline \multirow{2}{*}{$\begin{array}{c}\text { Patient } \\
1\end{array}$} & \multirow{2}{*}{$\begin{array}{l}\text { Age } \\
\text { 30-35 }\end{array}$} & \multirow{2}{*}{$\begin{array}{l}\text { Sex } \\
\text { Male }\end{array}$} & \multirow{2}{*}{$\begin{array}{l}\text { Eye } \\
\text { Left }\end{array}$} & \multirow{2}{*}{$\begin{array}{l}\begin{array}{l}\text { Associated } \\
\text { ocular conditions }\end{array} \\
\text { Atopy }\end{array}$} & \multirow{2}{*}{$\begin{array}{l}\begin{array}{l}\text { Lens } \\
\text { status }\end{array} \\
\text { IOL }\end{array}$} & \multicolumn{2}{|c|}{ GRT location } & \multirow{2}{*}{$\begin{array}{l}\text { GRT } \\
\text { size }\end{array}$} & \multirow{2}{*}{$\begin{array}{l}\text { Macula } \\
\text { On }\end{array}$} & \multirow{2}{*}{$\begin{array}{l}\begin{array}{l}\text { Preoperative } \\
\text { visual acuity }\end{array} \\
20 / 20\end{array}$} \\
\hline & & & & & & Temporal & $12: 00-6: 00$ & & & \\
\hline 1 & $30-35$ & Male & Right & Atopy & IOL & Inferior & $4: 00-8: 00$ & 120 & On & $20 / 20$ \\
\hline 2 & $30-35$ & Male & Right & Trauma & Phakia & Superior & $9: 00-1: 00$ & 120 & Off & HM \\
\hline 3 & $45-50$ & Male & Left & None & Phakia & Temporal & $1: 00-4: 00$ & 90 & Off & $20 / 30$ \\
\hline 4 & $30-35$ & Male & Right & None & Phakia & Temporal & $7: 30-10: 30$ & 90 & Off & $\mathrm{LP}$ \\
\hline 5 & $45-50$ & Male & Right & None & Phakia & Temporal & $7: 00-11: 00$ & 120 & Off & $\mathrm{HM}$ \\
\hline 6 & $35-40$ & Male & Left & Atopy & Phakia & Superior & $10: 00-3: 00$ & 150 & On & $20 / 60$ \\
\hline 7 & $20-25$ & Male & Right & None & Phakia & Superior & $10: 00-4: 00$ & 180 & On & $20 / 2,000$ \\
\hline 8 & $60-65$ & Male & Left & None & Phakia & Superior & $10: 00-2: 00$ & 120 & On & $20 / 25$ \\
\hline 9 & $40-45$ & Male & Left & None & Phakia & Temporal & $1: 30-4: 30$ & 90 & Off & $20 / 200$ \\
\hline 10 & $50-55$ & Male & Right & None & Phakia & Superior & $11: 00-2: 00$ & 90 & On & $\mathrm{CF}$ \\
\hline 11 & $50-55$ & Male & Right & None & Phakia & Temporal & $7: 00-1: 00$ & 180 & On & $\mathrm{CF}$ \\
\hline 12 & $70-75$ & Female & Left & Globe rupture & Aphakia & Temporal & $2: 00-5: 00$ & 90 & On & LP \\
\hline 13 & $55-60$ & Male & Right & None & IOL & Temporal & $8: 00-11: 00$ & 90 & Off & $20 / 16$ \\
\hline 14 & $20-25$ & Male & Left & Trauma & Phakia & Superior & $9: 00-12: 00$ & 90 & Off & $20 / 16$ \\
\hline 15 & $55-60$ & Male & Right & None & IOL & Inferior & $10: 00-1: 00$ & 90 & On & $\mathrm{HM}$ \\
\hline 16 & $35-40$ & Male & Right & Trauma & Aphakia & Temporal & $7: 00-11: 00$ & 120 & On & LP \\
\hline 17 & $20-25$ & Male & Left & Trauma & Phakia & Superior & $10: 00-2: 00$ & 120 & On & LP \\
\hline 18 & $15-20$ & Male & Left & Atopy & Phakia & Nasal & 7:00-11:00 & 120 & Off & $20 / 25$ \\
\hline 19 & $70-75$ & Male & Right & None & Phakia & Superior & $10: 00-1: 00$ & 120 & Off & $20 / 16$ \\
\hline
\end{tabular}

Patient ages are given as a range rather than exact ages to ensure anonymity. GRT, giant retinal tear; IOL, intraocular lens; HM, hand motion; LP, light perception; AKC, atopic keratoconjunctivitis; $\mathrm{CF}$, counting finger.

the advent of perfluorocarbon liquid (PFCL) [1]. Injection of PFCL into the vitreous cavity made it possible to reposition the rolled retina, even if the patient was in a supine position during the surgery, and contributed to a dramatic improvement in surgical outcomes $[2,3]$. In recent years, relatively good surgical outcomes for GRT detachment have been reported even in microincision vitreous surgery with the aid of PFCL $[4,5]$.

However, PFCL sometimes migrates through the retinal break into the subretinal space during surgery, especially in cases with large retinal breaks $[2-4,6,7]$. When PFCL remains in the fovea, its toxicity causes severe vision deterioration [6-8]. There is currently no established method for removing PFCL from under the retina [8]. Therefore, it is desirable to develop a new surgical method for GRT detachment treatment that would minimize the risk of PFCL retention.

We believed that endoscope-assisted pars plana vitrectomy (PPV) could significantly reduce the risk of PFCL retention in GRT detachment surgery. We have previously reported the following advantages of endoscope-assisted vitreous surgery. First, using the endoscope, it is possible to thoroughly drain the subretinal fluid without the use of PFCL, by turning the patient's head in a position such that the primary retinal breaks are placed at the lowest part of the eyeball $[9,12]$. In addition, vitreous surgery under air can suppress the movement of the detached retina using the air-vitreous interface without PFCL [11]. The slipped and rolled retina is stretched out using a silicone-tip backflush needle, by the air surface tension, without PFCL. In this study, we evaluated the surgical outcomes of endoscope-assisted microincision vitrectomy used in the treatment of GRT detachment.

\section{Materials and Methods}

\section{Patients}

We retrospectively reviewed the data pertaining to 20 consecutive eyes from 19 patients ( 1 woman and 18 men; average age: $42.8 \pm 16.0$ years) who underwent 23 or $25 \mathrm{G}$ endoscope-assisted PPV for the treatment of GRT detachment at the Japan Community Healthcare Organization Chukyo Hospital from October 2011 to June 2019. The minimum follow-up period was 3 months. The range of baseline best-corrected visual acuity was light perception to $17 / 20$ (Table 1). GRT was defined as a retinal tear extending over $90^{\circ}$. 


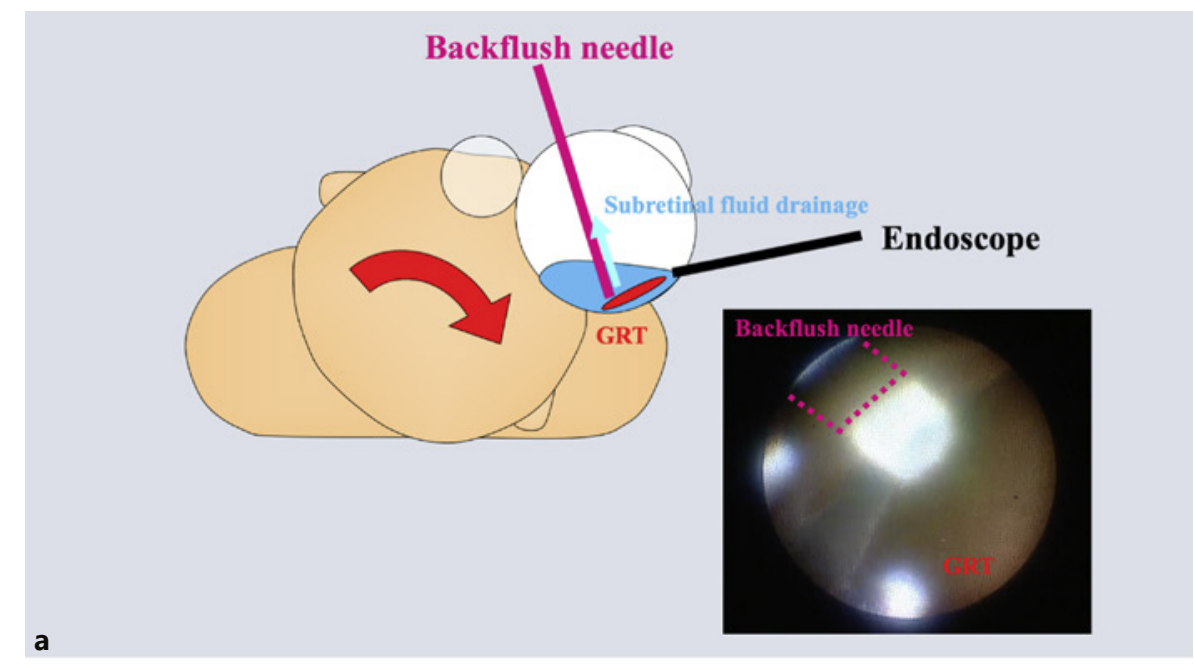

b

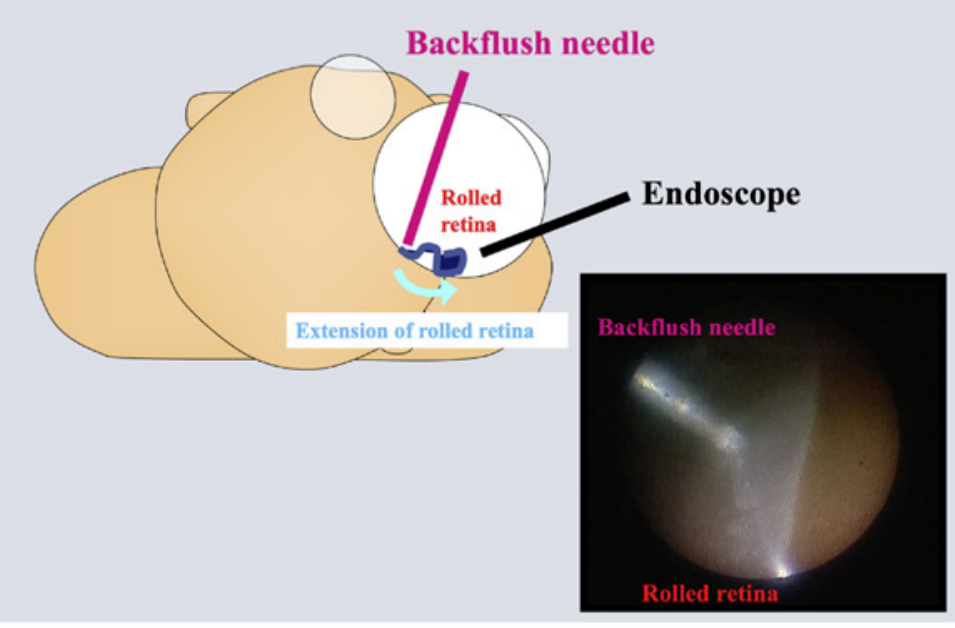

Fig. 1. Schematic images of endoscope-assisted vitreous surgery for GRT detachment. a First, the patient's head was moved toward the position where the GRT was located, at the lowest level. In this position, subretinal fluid can easily flow from the retinal break into the vitreous space. We inserted the backflush needle with a silicone tip from the higher positioned port and the ophthalmic endoscopic probe from the lower positioned port. b Then, the rolled retina was unfolded using a backflush needle, under air. c Finally, the patient's head was returned to the original position, and endolaser photocoagulation was performed around the primary retinal break, under air. GRT, giant retinal tear.

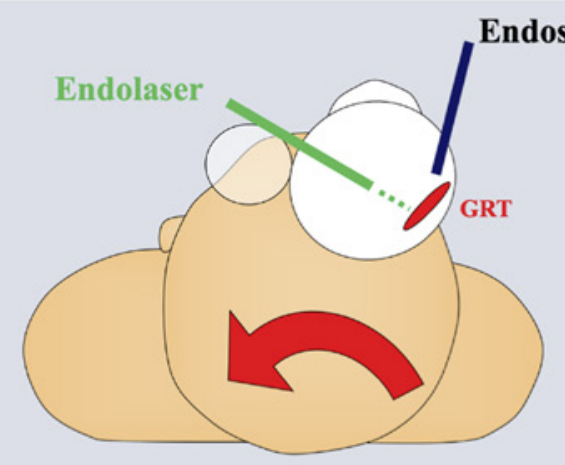

\section{Surgical Technique}

Six surgeons performed all the surgeries. All surgical procedures were performed under topical and regional anaesthesia, using anaesthetic eye drops and sub-Tenon's block. In phakic eyes, standard phacoemulsification and aspiration was performed in cases where visualization of the patient's fundus was poor due to cataract or there was a risk of progression of the nuclear cataract after surgery. All patients underwent a standard 3-port 23 or 25G 
PPV using the Constellation ${ }^{\circledR}$ Vision System (Alcon Laboratories, Inc., Fort Worth, TX, USA) or Fortas CV-30000 ${ }^{\circledR}$ (Nidek Co., Ltd., Aichi, Japan). A noncontact wide fundus viewing system (Resight ${ }^{\circledR} 700$; Carl Zeiss Meditec AG, Jena, Germany) and the imaging system (camera and light source) of an ophthalmic endoscope (FC-304/FL-30127; FiberTech, Tokyo, Japan) were used for visualization. We used an ophthalmic surgery chair (Mepro; Takara Belmont, Osaka, Japan), which can facilitate the change in a patient's position. In all eyes, a core vitrectomy and peripheral vitreous dissection was performed under Resight ${ }^{\circledR}$ or endoscope visualization, according to the surgeon's discretion. Then, an endoscope and a backflush needle with a silicone tip were inserted. The patient's head position was turned so that the primary retinal breaks were placed at the lowest part of the eyeball. This was done by adjusting the position of the movable surgical chair and the patient's posture. The subretinal fluid accumulated at the lowest part of the eyeball due to gravity was drained through the primary retinal breaks during the fluid-air exchange (Fig. 1a). The slipped and rolled retina was stretched out as a result of the retinal weight and air surface tension while scraping with a silicone-tip backflush needle under air, without the use of PFCL (Fig. 1b). After the subretinal fluid was sufficiently drained, the patient was returned to the original supine position. Photocoagulation was performed at the edge of the retinal break (Fig. 1c). Then, the entire fundus was inspected under endoscope for any additional retinal tears, which if found were treated with laser. The vitreous dissection around the original tear, subretinal fluid drainage, restoration of the rolled retina, endolaser photocoagulation, and fundus inspection were performed under endoscopic observation in all cases (see online suppl. Video; for all online suppl. material, see www.karger.com/ doi/10.1159/000517353). Then, the vitreous cavity was filled with one of the following: air, sulphur hexafluoride (SF6) gas, perfluoropropane (C3F8) gas, or silicone oil (SO) (SILIKON ${ }^{\circledR} 1000$ Oil; Alcon). "The intraocular filling material was determined intraoperatively by the surgeon according to the severity of the retinal detachment." At the end of surgery, the cannulas were removed, and sclerotomies were closed using 8-0 polyglactin 910 sutures (Vicryl ${ }^{\circledR}$; Ethicon, Somerville, NJ, USA), if necessary. The patients were instructed either to maintain a prone position or a position such that the original retinal breaks would be in the uppermost position, for 3-7 days. The SO was removed about 3 months after the initial surgery.

\section{Outcome Measures}

Retinal reattachment was evaluated at 3 months after surgery. For the eyes where SO was injected during the vitrectomy, the reattachment was evaluated 3 months after its removal. The outcome measures included anatomical success, visual acuity, and postoperative complications.

\section{Statistical Analyses}

The Snellen visual acuity values were converted from decimal to visual acuity values using the Landolt ring chart, and these visual acuity values were then converted to the logarithm of the minimum angle of resolution chart for analysis. Statistical analysis was performed using GraphPad Prism (GraphPad Software, San Diego, CA, USA). The Wilcoxon signed rank test was applied to compare the visual acuity before and after surgery. A $p<0.05$ was considered to be statistically significant.

Endoscope-Assisted Vitreous Surgery for Giant Retinal Tear Detachment

\section{Results}

Table 1 summarizes the patients' baseline characteristics. The study included 20 eyes from 19 patients ( 18 men and 1 woman), with a mean age of $42.8 \pm 16.0$ years (range, 18-74 years). Three patients (patients 1, 6, and 18) had a history of atopic dermatitis, patients 2 and 14 had histories of ocular blunt trauma (they were boxers and had been hurt by a punch to the face during a boxing match and training), and patient 12 had a history of globe rupture prior to the retinal detachment. While she was working on the farm, the gardening pillar was stuck into her eyeball and perforated the sclera. Patient 16 injured his eye with a broken tree branch during logging work.

Patient 17 was injured by an accidental stream of water in his eyes while cleaning the ship with a high-pressure washer hose. The lens status was "phakic" in 14 eyes, "pseudophakic" in 4 eyes, and "aphakic" in 2 eyes. The mean size of the GRT was $119^{\circ}$ (range, $90-180^{\circ}$ ). The GRT was located temporally in 9 eyes, superiorly in 8 eyes, inferiorly in 2 eyes, and nasally in 1 eye. The retinal detachment involved the macula in only 9 eyes.

Table 2 summarizes the intraoperative data and postoperative outcomes. During the first surgery, tamponade was performed in 8 eyes using SO (40\%), in 6 eyes using SF6 gas (30\%), in 5 eyes using air (25\%), and in 1 eye using C3F8 gas (5\%). Phacoemulsification and aspiration was performed in 8 eyes during the first surgery. In the subsequent surgery, an encircling scleral buckle was placed in 2 eyes (10\%). In this study, cryopexy was not performed in either eye; all eyes underwent endolaser photocoagulation. Further vitrectomy was required in 4 eyes (patients $2,7,11$, and 16) due to retinal re-detachment. With the exception of 1 eye (patient 16) followed up under SO, all the retinas were reattached without any tamponade.

In patient 1, PFCL was used for the purpose of extending the fixed retinal fold; however, the fold did not extend. The retina was stretched out after the air-fluid exchange caused by the surface tension of the air and the stroke of the backflush needle. In patient 2, PFCL was used for fixation of the detached macula to safely perform the inner limiting membrane peeling. In patient 16, PFCL was used to fix the total detached retina and remove the proliferative membrane during reoperation.

Postoperatively, there was no PFCL retained in either of the 3 patients. The SO was later removed in all cases except 1 patient (patient 16). The mean follow-up duration was 18 months (range, 3-69 months), and there was no recurrence of retinal detachment at the last follow-up visit.

Ophthalmic Res 2021;64:820-827 
Table 2. Intraoperative data and postoperative outcomes

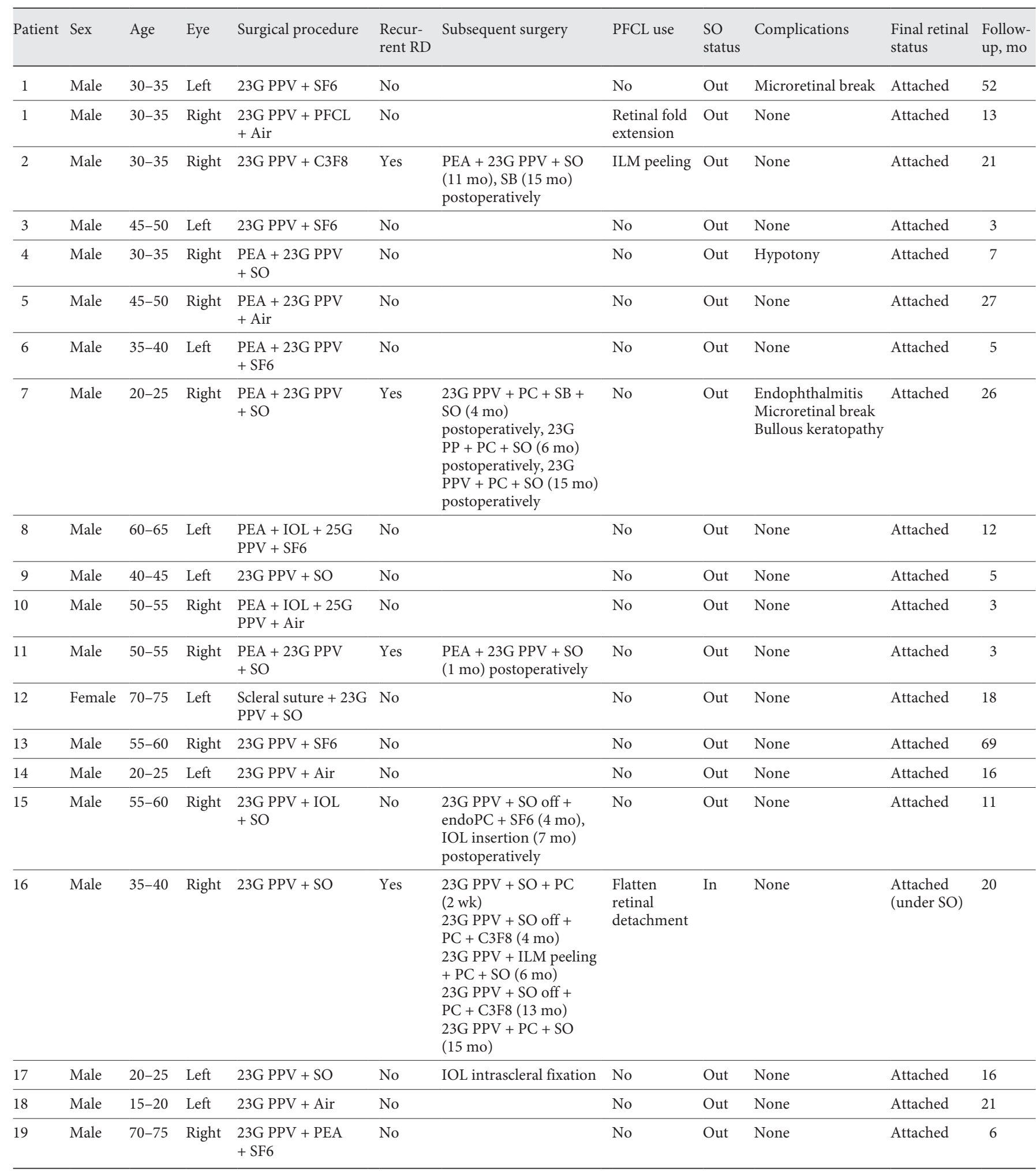

Patient ages are given as a range rather than exact ages to ensure anonymity. RD, retinal detachment; PFCL, perfluorocarbon liquids; SO, silicone oil; PPV, pars plana vitrectomy; SF6, sulphur hexafluoride; C3F8, octafluoropropane; PEA, phacoemulsification and aspiration; SB, scleral buckle; ILM, internal limiting membrane; IOL, intraocular lens. 


\section{Anatomical Success}

The primary and final anatomical success rates were $90.0 \%(18 / 20)$ and $95 \%(19 / 20)$, respectively.

\section{Visual Acuity}

Postoperative visual acuity improved in 16/20 (80\%) eyes and remained the same in $3 / 20(15 \%)$ eyes and $2 / 20$ $(10 \%)$ deteriorated. The mean best-corrected visual acuity significantly improved from $20 / 514$ preoperatively to $20 / 41$ postoperatively $(p=0.0008)$.

\section{Complications}

Retinal breaks occurred in 2 cases. These retinal breaks were small and were closed using photocoagulation. There was 1 (5\%) case of postoperative hypotony in this study. In this patient, there was no leakage from the PPV port, and no choroidal detachment was observed. The intraocular pressure spontaneously normalized on the 3rd postoperative day. One patient (5\%) had bullous keratopathy after multiple surgeries.

\section{Discussion/Conclusion}

During conventional microscopic surgery for GRT detachment, PFCL is injected over the level of the edge of the retinal tears to unfold and flatten the retina $[2,5]$. Even if the rolled retina is repositioned under the PFCL, retinal slippage and PFCL migration into the subretinal space sometimes occur during the complicated surgical procedures when PFCL is removed and replaced with a tamponade substance, such as SO $[5,6,11]$.

Conversely, in endoscopic vitrectomy, it is possible to tilt the patient's head so that the GRT is located at the lowest point in the eyeball, and complete subretinal fluid drainage can be done under air, without PFCL $[9,12$, 13]. We found that, in this position, the rolled retina was easily extended by a gentle stroke of a backflush needle without PFCL. Once the retina was unrolled, retinal slippage did not occur, even if the patient's head was returned to its original position before photocoagulation. Subsequent gas or SO tamponade was performed without any difficulty.

Significant improvement in visual acuity was achieved after the surgery, likely due to the complete retinal reattachment and the rare postoperative complications. The final reattachment rate (95\%) in this study is comparable to that reported in previous studies $(81.8-100 \%)$ [3, 13-17]. However, in one of the patients (patient 11), retinal attachment was not achieved after the initial sur-

Endoscope-Assisted Vitreous Surgery for Giant Retinal Tear Detachment gery. This patient had a giant retinal detachment on the temporal side, and 1 month following surgery, an anterior PVR occurred on the nasal side. A thorough peripheral $360^{\circ}$ vitrectomy in the initial surgery might have prevented the anterior PVR.

In patient 2 , the retina was attached following the initial surgery; however, re-detachment occurred due to a new retinal tear immediately after a head injury during a boxing match. We suspected that the direct ocular trauma caused the re-detachment.

In patient 7, the retina was also attached following the initial surgery; however, several re-detachments occurred during the follow-up period. The reason was not immediately apparent, as the patient did not immediately divulge that he had been scratching the eyes severely after the surgery. Since the provided postoperative eye patch exacerbated the inflammation of the eyelid skin, protective glasses were used instead. Thereafter, the itching gradually disappeared, and there were no further re-detachments.

In patient 16 , postoperative hyphema and vitreous haemorrhage were prolonged after the first surgery, and reoperation was performed approximately 2 weeks after the initial surgery to eliminate the vitreous haemorrhage. During the surgery, total retinal detachment was revealed, and after the detached retina was flattened with PFCL, vitrectomy and proliferative membrane resection were performed, and SO was injected. Since the retina was attached under SO for about 4 months, the SO was removed, and the postoperative course was good for 2 months. However, during the outpatient followup, there was a gradual proliferative change on the nasal side of the retina, and traction retinal detachment occurred, and reoperation was performed. The proliferative membrane and subretinal fluid in the eye were removed, and SO was injected. Since then, the retina has been attached under $\mathrm{SO}$, and the visual acuity has been maintained. The patient is being followed up without removal of the SO.

Although vitrectomy under air has been reported to be effective in terms of retinal stabilization and identification of the vitreous, visualization of the retina can be severely compromised in certain situations $[18,19]$. In that respect, using an endoscope allows for observation in close proximity to the retina, even under air, which means that a detailed visualization is obtained regardless of any difficulties, such as a corneal oedema, small pupil, lens opacity, and limited focus range of the microscope and wide field viewing system. By extending the retina using the surface tension of air, we accu- 
rately performed repositioning of the rolled retina and photocoagulation.

There were no cases of retained PFCL after surgery. In patient 1 who had PVR, we used PFCL in a limited area for extension of the fixed retina. Patient 2 had macular detachment at the time of reoperation, and in order to perform inner limiting membrane peeling of the macula more safely, PFCL was injected into the macular arcade to stabilize the detached retina. Since PFCL was not injected to a height exceeding the GRT in both cases, we believe that PFCL did not migrate under the retina.

The major limitations of this research are its retrospective design, and the limited number of cases studied. Moreover, a total of 6 different surgeons performed the surgeries. The intraocular filling material was determined intraoperatively based on the surgeon's judgement, not on clear criteria.

The disadvantages of the endoscope itself are a narrow observation range and low resolution, as well as lack of stereoscopic viewing. For example, it is difficult to perform ILM peeling of the detached macular retina under endoscopic observation, and it may be safer to perform ILM peeling while suppressing the mobility of the retina with PFCL under microscopic observation. In conclusion, our endoscope-assisted vitreous surgery enables favourable retinal reattachment and visual acuity improvement in GRT detachment.

\section{Statement of Ethics}

The surgical and experimental protocols were reviewed and approved by the Institutional Review Board of Japan Community Healthcare Organization Chukyo Hospital (\#20180399). Written informed consent was obtained from all participants, and the study conduct adhered to the tenets of the Declaration of Helsinki.

\section{Conflict of Interest Statement}

Dr. Kojima reports personal fees from Staar Surgical, personal fees from Santen Pharmaceutical, personal fees from Otsuka Pharmaceutical, personal fees from Johnson \& Johnson, and personal fees from Alcon, outside the submitted work. Dr. Ichikawa reports personal fees from Staar Surgical, personal fees from Santen Pharmaceutical, grants and personal fees from HOYA, personal fees from ZEISS, grants and personal fees from Alcon, personal fees from NIDEK, personal fees from KY CenterVue, other from Igaku Shoin, personal fees from Kowa, grants from JFC, personal fees from Novartis Pharma, and grants from MANI, outside the submitted work.

\section{Funding Sources}

The authors did not receive any funding relevant to this study.

\section{Author Contributions}

All authors met the 4 conditions shown in the ICMJE Criteria for Authorship. Conception or design of the work: H. Mitamura, T. Kaga, T. Kojima, and K. Ichikawa. Data collection: H. Mitamura, T. Kaga, S. Yokoyama, T. Mori, T. Matsuda, H. Sato, and N. Yoshida. Data analysis and interpretation: H. Mitamura and T. Kojima. Drafting the article: H. Mitamura, T. Kaga, S. Yokoyama, T. Kojima, T. Mori, T. Matsuda, H. Sato, and N. Yoshida. Critical revision of the article: T. Kaga, T. Kojima, N. Yoshida, H. Sato, T. Matsuda, S. Yokoyama, and K. Ichikawa. Final approval of the version to be published: H. Mitamura, T. Kaga, T. Kojima, T. Mori, N. Yoshida, H. Sato, T. Matsuda, S. Yokoyama, and K. Ichikawa.

\section{References}

1 Peyman GA. A new operating table for the management of giant retinal breaks. Arch Ophthalmol. 1981;99:498-9.

2 Chang S, Lincoff H, Zimmerman NJ, Fuchs W. Giant retinal tears. Surgical techniques and results using perfluorocarbon liquids. Arch Ophthalmol. 1989;107:761-6.

3 Scott IU, Murray TG, Flynn HW Jr, Feuer WJ, Schiffman JC; Perfluoron Study Group. Outcomes and complications associated with giant retinal tear management using perfluoron-octane. Ophthalmology. 2002;109:182833.

4 Kunikata H. Management of giant retinal tears using microincision vitrectomy surgery. Dev Ophthalmol. 2014;54:182-7.
5 Berrocal MH, Chenworth ML, Acaba LA. Management of giant retinal tear detachments. J Ophthalmic Vis Res. 2017;12:93-7.

6 Garcia-Valenzuela E, Ito Y, Abrams GW. Risk factors for retention of subretinal perfluorocarbon liquid in vitreoretinal surgery. Retina. 2004;24:746-52.

7 Mendez-Martinez S, Calvo P, RodriguezMarco, Faus F, Abecia E, Pablo L. Blindness related to presumed retinal toxicity after using perfluorocarbon liquid during vitreoretinal surgery. Retina. 2018;38:1856-64.

8 Le Tien V, Pierre-Kahn V, Chauvaud D, Chauvaud D. Displacement of retained subfoveal perfluorocarbon liquid after vitreoretinal surgery. Arch Ophthalmol. 2008;126:98101.
9 Yokoyama S, Kojima T, Mori T, Matsuda T, Sato H, Yoshida N, et al. Clinical outcomes of endoscope-assisted vitrectomy for treatment of rhegmatogenous retinal detachment. Clin Ophthalmol. 2017;11:2003-10.

10 Sonoda Y, Yamakiri K, Sonoda S, Uchino E, Doi N, Sakamoto T. Endoscopy-guided subretinal fluid drainage in vitrectomy for retinal detachment. Ophthalmologica. 2006;220:83-6.

11 Kaga T, Yokoyama S, Kojima T, Mitamura H, Mori T, Matsuda T, et al. Novel endoscopeassisted vitreous surgery combined with atmospheric endoscopic technique and/or subretinal endoscopic technique for rhegmatogenous retinal detachment with grade $\mathrm{C}$ proliferative vitreoretinopathy. Retina. 2019; 39:1066-75. 
12 Wong D, Williams RL, German MJ. Exchange of perfluorodecalin for gas or oil: a model for avoiding slippage. Graefes Arch Clin Exp Ophthalmol. 1998;236:234-7.

13 Goezinne F, LAH EC, Berendschot TT, Gast ST, Liem AT, Lundqvist IL, et al. Low redetachment rate due to encircling scleral buckle in giant retinal tears treated with vitrectomy and silicone oil. Retina. 2008;28:485-92.

14 Ambresin A, Wolfensberger TJ, Bovey EH. Management of giant retinal tears with vitrec- tomy, internal tamponade, and peripheral 360 degrees retinal photocoagulation. Retina. 2003;23:622-8.

15 Rofail M, Lee LR. Perfluoro-n-octane as a postoperative vitreoretinal tamponade in the management of giant retinal tears. Retina. 2005;25:897-901.

16 Sirimaharaj M, Balachandran C, Chan WC, Hunyor AP, Chang AA, Gregory-Roberts J, et al. Vitrectomy with short term postoperative tamponade using perfluorocarbon liquid for giant retinal tears. Br J Ophthalmol. 2005;89: 1176-9.

17 Shunmugam M, Ang GS, Lois N. Giant retinal tears. Surv Ophthalmol. 2014;59:192-216.

18 Voleti VB, Gee CJ, Devin F, Hubschman JP. Vitrectomy under air. Retina. 2012;32:1981-2.

19 Altan T, Ozbilen KT, Cetin T, Kapran Z. Results of peripheral vitrectomy under air in rhegmatogenous retinal detachment. Ophthalmic Surg Lasers Imaging Retina. 2017;48: 51-4. 